\title{
Influences of castration and testosterone on spring to summer changes in release of luteinizing-hormone-releasing hormone in rabbits
}

\author{
W. W. Lin and V. D. Ramirez \\ Department of Physiology and Biophysics, 524 Burrill Hall, University of Illinois, \\ 407 S. Goodwin Avenue, Urbana, IL 61801, USA
}

\begin{abstract}
Summary. Push-pull cannulae were implanted toward the tuberal region of the hypothalamus in ten intact New Zealand male rabbits. In the first experiment, rabbits were perfused at different times after castration: $5-10$ days $(n=10), 22-31$ days $(n=9)$
\end{abstract} and 50-64 days $(n=8)$.

The release, mean amplitude and mean frequency of luteinizing-hormone-releasing hormone (LHRH) signals from 37 perfusions in ten animals were analysed in intact rabbits and at different times after castration. No significant changes in release of LHRH and in amplitude were observed, but the frequency was significantly higher 22-31 days after castration than in intact rabbits (intact: $0.86 \pm 0 \cdot 12$; castrated: $1 \cdot 20 \pm 0.13$ pulses $\mathrm{h}^{-1}, P<0.035 ; n=9$ ).

In Expt 2, testosterone and placebo Silastic capsules were implanted in the castrated rabbits. Perfusions were performed in the following four periods, defined by season and time after testosterone and placebo implants: (i) spring; before implants, (ii) late spring; 0-2 weeks after implants, (iii) summer solstice; $2-4$ weeks after implants and (iv) summer; 4-6 weeks after implants. Castrated rabbits were perfused during spring; castrated rabbits with testosterone capsule implants were perfused during late spring, around summer solstice and in summer and castrated rabbits with placebo implants were perfused during periods (iii) and (iv). Castrated animals with placebo implants showed no significant changes in mean LHRH release and amplitude, although the frequency was significantly higher around the summer solstice period than in castrated rabbits perfused in the spring. In castrated rabbits with testosterone implants LHRH release was significantly higher in late spring than around the summer solstice and in the summer. In addition, the concentrations of LHRH in late spring were significantly higher than those of intact and castrated animals. In contrast, mean LHRH amplitude and frequency did not change. Mean amount of LHRH released and amplitude in castrated rabbits with testosterone implants were significantly lower around the summer solstice than in late spring or summer and compared with intact animals around summer solstice and in castrated rabbits in early spring.

These data demonstrate that there were no significant changes in the mean amplitude and release of LHRH after castration from 5 and up to 64 days in rabbits with hypothalamic push-pull cannulae, in contrast to the well established dramatic effect of castration on gonadotrophin concentrations. However, there was a small, but significant, increase in the mean frequency of LHRH pulses 22-31 days after castration compared with values from intact rabbits. In addition, testosterone may be an important stimulator of LHRH release in castrated rabbits although its effect is transient. Episodic release of testosterone may be crucial for regulation of seasonal changes in the LHRH pulse generator in male rabbits. 
Keywords: LHRH; push-pull cannulae; testosterone; rabbit

\section{Introduction}

Seasonal changes in concentration of testosterone and gonadotrophin, testicular size and fecundity have been well documented in wild rabbits (Elder \& Finerty, 1943; Davis \& Meyer, 1973a; Lincoln, 1976; Boyd \& Myhill, 1987). Gonadotrophin concentrations increase with testicular weight during the spring and summer and decline during the autumn, reaching minimum values at about the winter solstice. These seasonal changes have also been observed in domesticated rabbits (Carson \& Amann, 1972; Reed, 1979). We have examined the seasonal changes in the activity of the luteinizing-hormone-releasing hormone (LHRH) pulse generator in New Zealand White rabbits in vivo using push-pull cannulae (Lin \& Ramirez, 1991). These studies demonstrated that marked increases in LHRH activity occur during and immediately after the summer solstice in male New Zealand White rabbits, followed by marked decreases in LHRH activity at about the winter solstice. These seasonal changes are due to changes in the amplitude as well as frequency of LHRH pulses, which may reflect an increase in the synthesis of LHRH, a synchronization of LHRH neuronal activity or both. The possible role of testosterone in this process was addressed in this study.

Previous studies have shown that bilateral castration in New Zealand White rabbits result in 2-6-fold increases in concentrations of luteinizing hormone $(\mathrm{LH})$ and follicle-stimulating hormone (FSH) (Moor \& YoungLai, 1975; YoungLai, 1978; Limonta et al., 1986) as well as LHRH receptors (Limonta et al., 1986). These effects of castration can be prevented by androgen replacement (Limonta et al., 1986). Boyd (1987) found that castration does not eliminate the photoperiodic influence on gonadotrophin release in wild rabbits. The possible occurrence of seasonal changes in LHRH release around the summer solstice in long-term castrates with or without testosterone replacement was therefore studied.

\section{Materials and Methods}

\section{Animals}

Sexually mature male New Zealand White rabbits $(3.34 \pm 0.12 \mathrm{~kg} ; n=10)$, raised under natural lighting conditions and exposed to seasonal variation in light duration and changes in temperature $\left(5^{\circ} \mathrm{C}\right.$ in winter, $26^{\circ} \mathrm{C}$ in summer), were obtained from a local supplier (Johnson, Wilkenson, IN, USA). On arrival, rabbits were isolated and housed in airconditioned quarters, in a $12 \mathrm{~h}$ light:12 h dark cycle (lights on at $06: 00 \mathrm{~h}$ ) which was maintained throughout the study. In spite of this fixed lighting regimen rabbits showed clear seasonal changes (Lin \& Ramirez, 1991). All rabbits were provided with water and rabbit pellets ad libitum as well as supplements of fresh lettuce. Rabbits were kept in these conditions for at least 1 week before surgery.

\section{Implantation of the cannula}

Ten rabbits were used in this study; they were implanted with a push-pull cannula as described by Lin \& Ramirez (1988). On the day of implantation, animals were weighed and anaesthetized with a mixture of ketamine-xylazine (35.5 $\mathrm{mg} \mathrm{kg}^{-1}, 1: 1$, i.m.). Construction (Dluzen \& Ramirez, 1986) and implantation (Lin \& Ramirez, 1988, 1990) of the cannula were as described previously. The cannula was aimed towards the medial basal region of the hypothalamus using the following stereotaxic co-ordinates derived from the Rabbit Brain Atlas of Sawyer et al. (1954): $1 \mathrm{~mm}$ posterior from bregma, $1 \mathrm{~mm}$ lateral from the midline and $16.5 \mathrm{~mm}$ vertical from the calvarium. The cannula assembly was connected with polyethylene tubing (PE-20, Clay Adam's Co., Parsipany, NJ, USA) to two separate peristaltic pumps (Rabbit miniature peristaltic pumps, Rainin Instrument Corp., Woburn, MA, USA), one to push medium through the perfusion system and the other to pull medium at exactly the same flow rate $\left(10-14 \mu \mathrm{min}^{-1}\right.$, with most of the perfusions at about $12 \mu \mathrm{lmin}^{-1}$.

\section{Push-pull experiments}

On the day of perfusion, the animal was brought to the laboratory at about 10:00 h. The rabbit was placed in an open-top metal cage $\left(51.0 \times 45.5 \times 40.5 \mathrm{~cm}^{3}\right)$ with holes in the walls for air circulation. Within this cage, the animal 
was free to move, eat, drink and rest. Peristaltic pumps were adjusted to achieve a balanced flow rate between the push and pull cannulae while the animal adjusted to the new environment, which usually took about $1-2 \mathrm{~h}$. Filtered (Millipore Filter-45 $\mu \mathrm{M}$ ) modified Krebs-Ringer phosphate (KRP) medium, which consisted of (in mmol $\left.1^{-1}\right): 123 \mathrm{NaCl}, 4 \cdot 8 \mathrm{KCl}, 0.27 \mathrm{CaCl}_{2}, 1.2 \mathrm{MgSO}_{4}$ and 12 sodium phosphate buffer, $\mathrm{pH} 7 \cdot 4$, was used to perfuse the hypothalamic area of these rabbits.

\section{Experimental design}

This study consists of two groups of experiment in which ten male rabbits were subjected to 63 perfusion experiments with modified KRP medium for an average of $210 \mathrm{~min}$. These animals were perfused several times under various conditions to study the effect of castration on LHRH release (Expt 1) and the effect of long-term castration in rabbits with or without testosterone replacement on the seasonal changes in LHRH release during the summer solstice (Expt 2).

In Expt 1 , all ten rabbits were perfused as intact rabbits and during different periods after castration: $5-10$ days $(n=10), 22-31$ days $(n=9)$ and 50-64 days $(n=8)$. Rabbits were castrated under anaesthesia through bilateral small scrotal incisions (ketamine: $35 \mathrm{mg} \mathrm{kg}^{-1}$; xylazine $5 \mathrm{mg} \mathrm{kg}^{-1}$, i.m.) between 14 February and $8 \mathrm{May}$; the majority were castrated in March and April. Concentrations of testosterone after various periods of castration were measured using a radioimmunoassay in the laboratory of $\mathrm{J}$. Bahr (Bahr et al., 1983).

In Expt 2, testosterone and placebo Silastic capsule implants were implanted in long-term castrates $(69.5 \pm 7.64$ days) subcutaneously above the scapula under anaesthesia (ketamine: $35 \mathrm{mg} \mathrm{kg}^{-1}$; xylazine: $5 \mathrm{mg} \mathrm{kg}^{-1}$ ) on 5 and 6 June, respectively. The testosterone implants (provided by A. Ladd) consisted of Silastic capsules containing a rod of testosterone suspended in a mixture containing the steroid and Special Silastic 382 (Dow Corning Corp., Midland, MI). Two $2.0 \mathrm{~mm}$ and one $0.7 \mathrm{~mm}$ Silastic capsule were implanted in each animal, achieving release rates of $250 \mu \mathrm{g}$ $\mathrm{kg}^{-1} \mathrm{day}^{-1}$ (for details see Limonta et al., 1986). An equal number of rabbits were randomly given either testosterone $(n=5)$ or placebo implants $(n=5)$. Perfusions were grouped into the following four periods, defined by season as well as by time after testosterone and placebo implants: (i) 24 March- 4 June (spring; period before implants), (ii) 5 June-19 June (late spring; 0-2 weeks after implants), (iii) 20 June-2 July (summer solstice period; $2-4$ weeks following implants) and (iv) 2 July-16 July (4-6 weeks after implants). Castrates were perfused during period (i), long-term castrates with implants were perfused during periods (ii), (iii) and (iv), and long-term castrates with placebo implants were perfused during periods (iii) and (iv).

Push-pull perfusate samples were collected every $10 \mathrm{~min}$ into tubes on ice, acidified with 1 mol $\mathrm{HCl}^{-1}$ to a final concentration of $0.1 \mathrm{~mol}^{-1}$ and frozen until LHRH measurements were performed by radioimmunoassay as previously reported (Hartter \& Ramirez, 1985). The intra-assay coefficient of variation in these assays at a dose of $1.0 \mathrm{pg}$ LHRH per tube was $4.9 \%$. The interassay coefficient of variation was $5.7 \%$ at the $5 \mathrm{pg}$ dose. The sensitivity of these assays was typically $0.5 \mathrm{pg}$ at $95 \%$ bound.

\section{Histology of brain tissue}

Animals were anaesthetized using ketamine-acepromazine $\left(60 \mathrm{mg} \mathrm{kg}^{-1} ; 1: 1\right.$ ratio) followed by ether. They were then perfused from the heart with saline, followed by formaldehyde-saline, and histological analyses were performed on brain slices as described previously (Ramirez et al., 1986). The cannula placements ranged from infundibular arcuate nucleus to positions lateral to the ventral medial nucleus (VMN).

\section{Statistical analysis}

The data from individual rabbits were analysed by the Pulsar program (Merriam $\&$ Wachter, 1982) for detection of pulses and mean output using a $10 \%$ error for the calculation of the $G$ values according to a normal distribution probability. The Pulsar program was adapted for an IBM-PC microcomputer in this laboratory by J. Gitzen (Gitzen \& Ramirez, 1987). Data were analysed by obtaining the mean release, mean amplitude and mean frequency from every perfusion. A Kruskal-Wallis one-way analysis of variance followed by the Mann-Whitney $U$ test were performed on these data, and a value of $\leqslant 0.05$ was required for results to be considered statistically significant. In addition, a Wilcoxon's signed rank test was used to compare perfusions performed in the same animals.

\section{Results}

Animals were perfused more than once without any detrimental effects; they were calm, resting or sleeping, but remained responsive to any ambient noise in the laboratory. They exhibited normal behaviour, such as standing, lying and sleeping, with periods of hopping, turning, eating, drinking and rearing.

\section{Experiment 1}

Testosterone concentrations remained at $<0.1 \mathrm{ng} \mathrm{ml}^{-1}$ in castrates regardless of the time since castration. In rabbit no. 161 , there was a slight increase in mean LHRH release ( 1.36 versus 
$1.80 \mathrm{pg}$ in $10 \mathrm{~min})$ and a slight decrease in mean amplitude (2.96 versus $2.17 \mathrm{pg}$ ) and frequency ( 1.30 versus 0.75 pulses $h^{-1}$ ) 6 days after castration (Fig. la). In contrast, 30 and 63 days after castration, both the mean LHRH release and mean amplitude decreased, but the frequency increased compared with values 6 days after castration. There were no changes in the mean LHRH pulse amplitude and mean LHRH after castration over a prolonged period in rabbit No. 162 (Fig. 1b), but the frequency increased after 27 days compared with that in the intact animal (intact: 0.90 versus castrate: 1.91 pulses $\mathrm{h}^{-1}$ ). In rabbit No. 159 (Fig. $2 \mathrm{a}$ ), there was a two-fold increase in mean LHRH release (intact: 0.81 versus castrate: $1.58 \mathrm{pg}$ in $10 \mathrm{~min}$ ), mean amplitude (intact: 1.15 versus castrate: $3.72 \mathrm{pg}$ ) and mean frequency (intact 0.52 versus castrate: 1.06 pulses $\mathrm{h}^{-1}$ ) 8 days after castration. The mean LHRH release and mean amplitude returned to intact values 28 days after castration $(0.97 \mathrm{pg}$ and $1.27 \mathrm{pg}$ in $10 \mathrm{~min}$, respectively). In contrast, the frequency continued to increase to 1.50 pulses $\mathrm{h}^{-1}$. These parameters remained stable at 64 days after castration. In rabbit No. 155 (Fig. 2b) increases were observed in the mean LHRH release (intact: 0.71 versus castrate: $1.42 \mathrm{pg}$ in $10 \mathrm{~min}$ ), mean LHRH pulse amplitude (intact: 1.02 versus castrate: $1.76 \mathrm{pg}$ ) and mean LHRH frequency (intact: 0.55 versus castrate: 1.80 pulses $\mathrm{h}^{-1}$ ), 10 days after castration. The mean LHRH release returned to previous intact levels $(0.70 \mathrm{pg}$ in $10 \mathrm{~min})$, whereas the mean amplitude dropped to values below intact values $(0.53 \mathrm{pg})$ in the third perfusion. However, as in rabbit No. 162, the frequency was still increased compared with intact values $\left(1.28\right.$ pulses $\left.h^{-1}\right)$. Overall, these four examples show the varied responses in the LHRH activity to castration. The data from 37 perfusions in 10 animals (mean \pm SEM) are summarized (Fig. 3). A Kruskal-Wallis one-way analysis of variance followed by the Mann-Whitney $U$ test were performed on these data, and an $\alpha \leqslant 0.05$ was required for results to be considered statistically significant. In addition, the Wilcoxon's matched pairs signed rank test was used to compare perfusions performed in the same animals. The mean LHRH release remained very stable after castration with mean values at about $1.00 \mathrm{pg}$ in $10 \mathrm{~min}$. The amplitude increased slightly 5-10 days after castration (intact: $1 \cdot 27 \pm 0 \cdot 23$ versus castrate: $1.46 \pm 0.33 \mathrm{pg}$ ) and dropped $22-31$ days after castration $(1.03 \pm 0.08 \mathrm{pg})$, although these changes were not statistically significant. The mean frequencies were higher after castration during all three periods compared with intact frequencies, reaching significance $22-31$ days after castration compared with intact values (intact: $0.86 \pm 0.12$ versus castrate: $1.20 \pm 0.13$ pulses h$^{-1}$, $P<0.035 ; n=9$ ) using the Wilcoxon's matched pairs signed rank test.

\section{Experiment 2}

In Expt 2, the seasonal changes in LHRH release around the summer solstice in long-term castrated rabbits with or without testosterone implants were examined. Blood testosterone concentrations were measured on 12 June and $18 \mathrm{July}$ in animals with testosterone implants and compared with those of intact animals $\left(1 \cdot 28-4.69 \mathrm{ng} \mathrm{ml}^{-1} ; n=4\right)$. Testosterone concentration was $2.56 \pm$ $0.46 \mathrm{ng} \mathrm{ml}^{-1}$ on $12 \mathrm{June}(n=5)$ and fell to $0.96 \pm 0.10 \mathrm{ng} \mathrm{ml}^{-1}$ on $18 \mathrm{July}(n=5), 7$ and 43 days after testosterone implants were given, respectively. However, in one of the intact rabbits sampled on day 43 , the concentrations were also lower $\left(1.28 \mathrm{ng} \mathrm{ml}^{-1}\right)$. Castrates $\left(0.07 \pm 0.009 \mathrm{ng} \mathrm{ml}^{-1}\right)$ and castrates with placebo implants $\left(0.072 \pm 0.006 \mathrm{ng} \mathrm{ml}^{-1}\right)$ both had significantly lower concentrations of blood testosterone compared with intact animals and castrated animals with testosterone replacements $(P<0 \cdot 001)$. In rabbit No. 161 (Fig. 1a), there were no significant changes around the summer solstice period after the placebo implants; in fact, the highest mean LHRH concentrations were observed 6 days after castration on 2 April 1990 (1.80 pg in $10 \mathrm{~min}$ ). In rabbit No. 162 (Fig. 1b), the mean LHRH release remained around $0.90 \mathrm{pg}$ in $10 \mathrm{~min}$ during all perfusions except on 4 July 1990 when the LHRH release levels dropped to $0.59 \mathrm{pg}$ in $10 \mathrm{~min}$.

In rabbit No. 159, which was given testosterone implant on 5 June (Fig. 2a), there was a marked increase in mean LHRH release 6 days after testosterone implants $(4.80 \mathrm{pg}$ in $10 \mathrm{~min})$ compared with concentrations of $1.05 \mathrm{pg}$ in $10 \mathrm{~min}$, whereas the mean amplitude and mean frequency remained stable. In contrast, 23 days after constant delivery of testosterone, mean LHRH release 
(a)

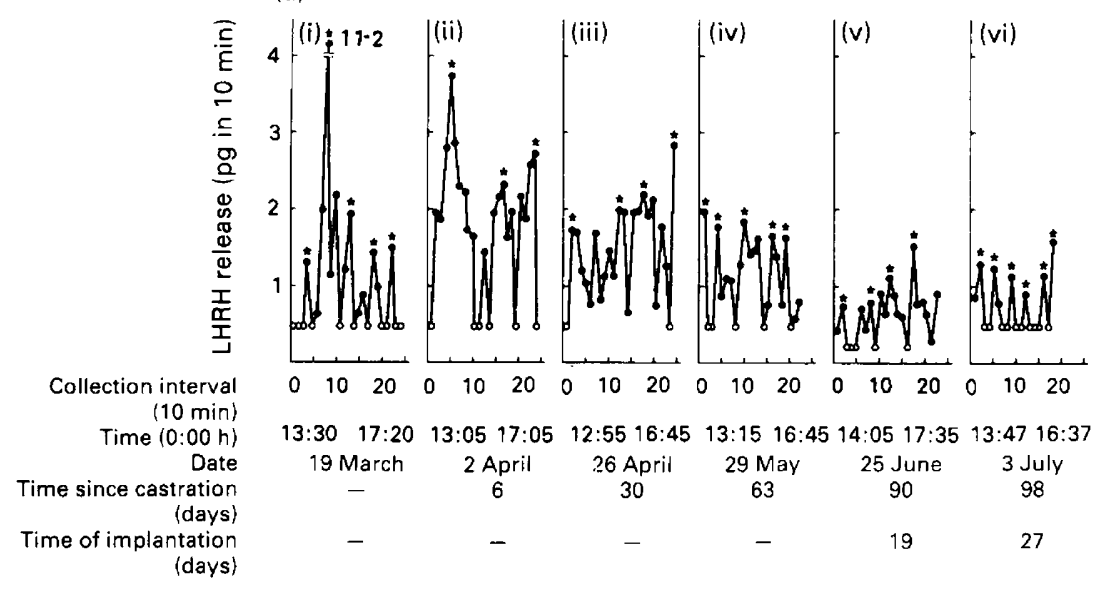

(b)

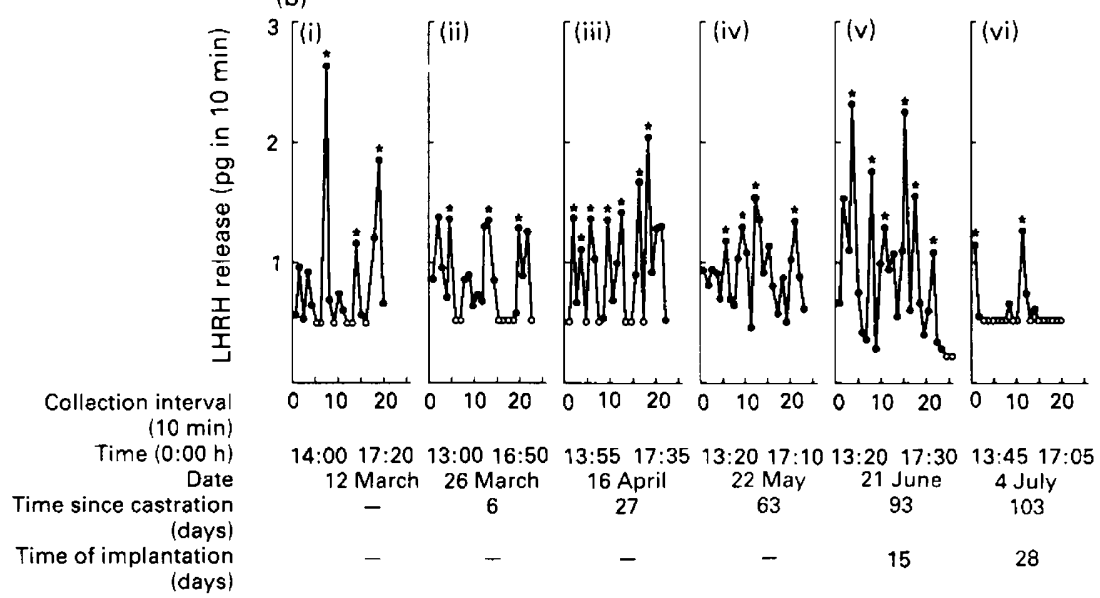

Fig. 1. Release of luteinizing-hormone-releasing hormone (LHRH) in vivo of (a) rabbit No. 161 repeatedly perfused from 19 March 1990 to 3 July 1990 and of (b) rabbit No. 162 repeatedly perfused from 12 March 1990 to 4 July 1990 with modified Krebs-Ringer phosphate buffer, while intact (i) and at different times after castration (ii-iv). During the last two perfusions ( $v$, vi) the rabbit also received a blank implant on 6 June. ${ }^{\star}$ Pulses detected by the PC-Pulsar program, (O) samples below the sensitivity of the assay which ranged from 0.2 to $0.5 \mathrm{pg}$ in $10 \mathrm{~min}$. The cannula placement of rabbit No. 161 was $2 \mathrm{~mm}$ lateral over the optical tract and in rabbit No. 162 between the ventromedial nucleus and arcuate nucleus. Both locations correspond to A-1 of the Rabbit Brain Atlas (Sawyer et al., 1954).

and amplitude decreased to very low levels $(0.47 \mathrm{pg}$ and $0.50 \mathrm{pg}$ in $10 \mathrm{~min}$, respectively). By 30 days after testosterone implants, these values were restored to those obtained before testosterone treatment. In rabbit No. 155 (Fig. 2b), there was a sevenfold increase in LHRH mean release levels, 8 days after testosterone implants compared with values before testosterone treatment. In addition, there was a threefold increase in mean amplitude. Again, this effect of testosterone was transient since the activity of the LHRH neurons reached values obtained before testosterone treatment after 22 days of constant testosterone delivery.

Regression lines of mean LHRH release, mean amplitude and mean frequency versus days after testosterone implants (Fig. 4) show a relatively rapid effect of testosterone implants on the mean 


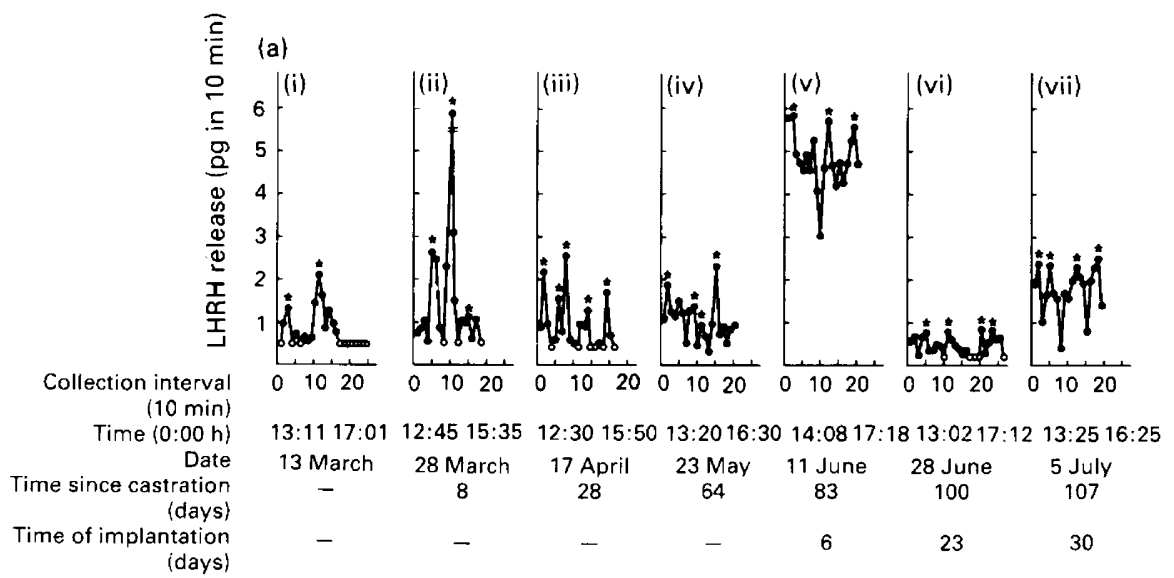

(b)

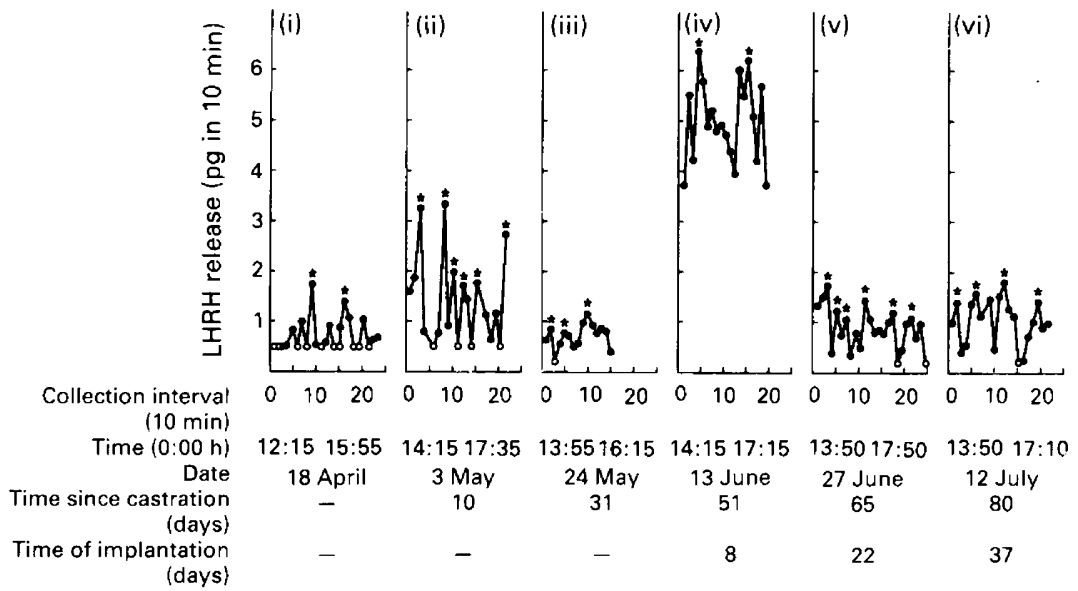

Fig. 2. Release of luteinizing-hormone-releasing hormone (LHRH) of (a) rabbit No. 159 in vivo repeatedly perfused from 13 March 1990 to 5 July 1990 and of (b) rabbit No. 155 repeatedly perfused from 18 April 1990 to 12 July 1990 with modified Krebs-Ringer phosphate buffer while intact (i) and following castration (ii-vii). In these animals testosterone implants were given on 5 June 1990 and perfused three times after testosterone implantation (iv-vi). The cannula placement in rabbit No. 159 was in the lower lateral ventromedial nucleus (VMN) and in rabbit No. 155 in the VMN. Both locations correspond to $\mathrm{A}-\mathrm{P}_{0}$ of the Rabbit Brain Atlas (Sawyer et al., 1954).

release of LHRH with peak values 6-8 days after implantation although this cannot be statistically evaluated.

\section{Discussion}

This study provides one of the first reports of the use of push-pull cannulae in male rabbits in an attempt to measure the effect of castration and testosterone replacement in the same animal and provides information about the LHRH pulse generator in male rabbits. First, castration does not alter the activity of the LHRH neurons since the mean amplitude and LHRH release did not change significantly after castration for up to 64 days except for a small but significant increase in 

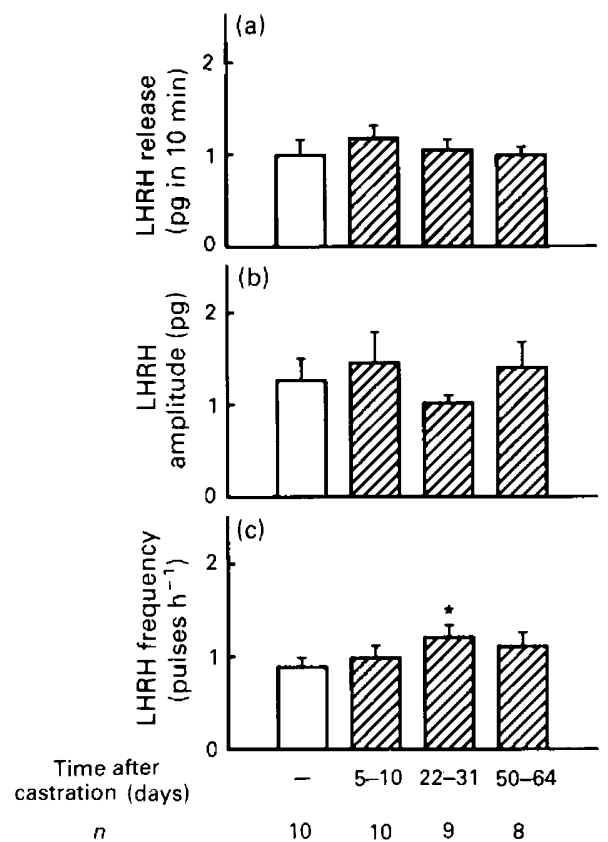

Fig. 3. Effect of castration on the activity of the LHRH pulse generator. (a) Luteinizinghormone-releasing hormone (LHRH) release (b) amplitude and (c) frequency of LHRH signals from 37 perfusions in ten rabbits (mean \pm SEM). All ten rabbits were perfused as intact $(\square)$ rabbits and during different periods after castration ( $\mathbb{Z}$ ). A Kruskal-Wallis one-way analysis of variance followed by the Mann-Whitney $U$ test were performed on these data, and an $\alpha$ value of $\leqslant 0.05$ was required for results to be considered statistically significant. In addition, the Wilcoxon's matched pairs signed rank test was used to compare perfusions performed in the same animals: Values significantly higher than those in intact animals using the Wilcoxon's matched pairs signed rank test. $n$ : number of rabbits in each block that were perfused during each period.

frequency. Second, the activity of the LHRH pulse generator in long-term castrates around the summer solstice did not change significantly, indicating that the marked increase in LHRH concentrations observed previously in intact rabbits (Lin \& Ramirez, 1991) were testes dependent. Third, although there was a significant increase in mean LHRH concentrations within two weeks following testosterone implants, the effect was rapid and transient and therefore this type of testosterone treatment could not restore the normal pattern of LHRH release observed in intact male rabbits around the summer solstice (Lin \& Ramirez, 1991). The effect of castration on concentrations of gonadotrophin in serum and pituitary $\mathrm{LHRH}$ receptors has been studied extensively in male rabbits (Moor \& YoungLai, 1975; YoungLai, 1978; Limonta et al., 1986; Boyd, 1987; Larsen \& Odell, 1987). Castration results in a rapid and large increase in serum concentrations of $\mathrm{LH}$ in rabbits (YoungLai, 1978; Limonta et al., 1986; Boyd, 1987, Larsen \& Odell, 1987). Detailed analyses of concentrations of LH in serum collected every 3-4 min showed that LH concentration and pulse amplitude increased after castration, but there was no effect on the pulse frequency (Larsen \& Odell, 1987). LH concentrations have been demonstrated to increase significantly 5 days after castration with maximum values occurring 8 days after castration. These high hormone concentrations persisted for the duration of the experiment or 4 weeks (Limonta et al., 1986). Other studies have also shown increases in LH concentrations after castration (Moor \& YoungLai, 1975; YoungLai, 1978) with high concentrations maintained 2 weeks after castration (YoungLai, 1978). There is an increase in the concentration of LHRH receptors, but the affinity $\left(K_{\mathrm{a}}\right)$ did not change (Limonta et al., 1986). 

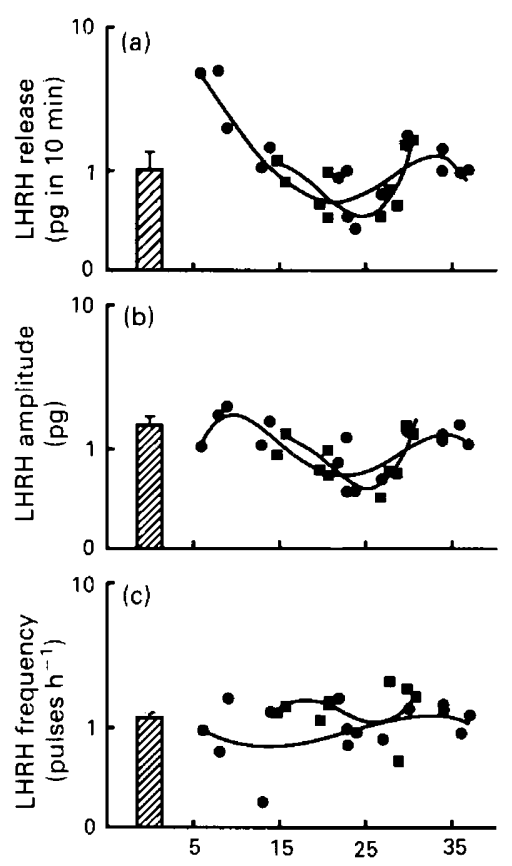

Time since testosterone implant (days)

Fig. 4. Regression plots of (a) mean LHRH release, (b) mean amplitude and (c) mean frequency versus days after testosterone implants in castrated rabbits. These plots show the effect of testosterone implants $(\bullet)$ as well as control placebo implants (ם) for individual perfusions. The mean values of perfusion before testosterone and placebo implants are represented by the bar graphs $(n=10)$.

In rats, many studies have challenged the notion that the effects of castration are at the level of the hypothalamus (for review, see Kalra \& Kalra, 1989). For example, it has been shown that in castrated rats, the overall mean LHRH release in animals bearing push-pull cannulae in the hypothalamus is very similar to that in intact rats. In addition, the amplitude and overall LHRH output of long-term castrated rats in vivo were markedly reduced and significantly lower than those in intact male rats while, as in rabbits, frequency increased (Dluzen \& Ramirez, 1985). However, LHRH output measured at the anterior pituitary, following castration, significantly increased (Dluzen \& Ramirez, 1987; Pickle \& Ramirez, 1989). Other studies have also shown that mean LHRH pulse amplitude and mean LHRH concentrations were not different in intact and castrated rats with push-pull cannulae in the hypothalamus (Levine \& Duffy, 1988). However, a modest increase in pulse frequency was demonstrated $24-30 \mathrm{~h}$ after castration (Levine \& Duffy, 1988). In addition, studies have shown a decrease in hypothalamic LHRH content following castration (for reviews, see Kalra \& Kalra, 1989; Culler et al., 1988). These results question the notion that the increase in concentrations of $\mathrm{LH}$ in blood of castrated male rats and rabbits are due to an increased amplitude and high LHRH release from the hypothalamus. It is possible, however, that following castration, there is an increased synchrony of LHRH release throughout the entire hypothalamus, resulting in an increased frequency and amplitude of LHRH signals arriving at the anterior pituitary (Dluzen \& Ramirez, 1987).

This study examined the effect of castration on LHRH release in male rabbits and demonstrated no obvious changes in the activity of the LHRH pulse generator despite the high concentrations of LH and FSH that have been reported in serum. In contrast, the effect of ovariectomy on LHRH release in the female rabbits with push-pull cannulae in the hypothalamus resulted 
in an increase in LHRH release, pulse amplitude and pulse frequencies (Pau et al., 1986). This marked sex difference in the response of the LHRH pulse generator to castration requires further investigation.

The period at which castration takes place in animals that are sensitive to photoperiodic changes has been investigated. Studies in hamsters (Turek et al., 1975) and rabbits (Caillol et al., 1990; Davis \& Meyer, 1973b) have demonstrated that the effect of castration depends on the photoperiod during which castration takes place. In the male golden hamsters, the rapid increase in serum LH and FSH concentrations normally seen after castration does not occur in hamsters maintained on nonstimulatory daylengths while concentrations increased in hamsters maintained on photostimulatory daylengths (Turek et al., 1975). Furthermore, in snowshoe hares, the hypothalamic pituitary axis is insensitive to the removal of gonadal steroids during the nonbreeding season whereas castration stimulated the pituitary during or just before the breeding season (Davis \& Meyer, 1973b). In addition, in castrated ewes, the negative feedback action of oestrogen on LH control clearly varies as a function of season (Legan \& Karsch, 1980). In female brown hares, during the breeding season, basal concentrations of LH increased within a few days after ovariectomy whereas a slower increase was observed in anoestrous rabbits (Caillol et al., 1990). In our study, animals were castrated during the breeding season, near the end of February, which is reportedly the most sensitive time for negative feedback effects of steroids on $\mathrm{LH}$ release.

There were no significant changes in the activity of the LHRH pulse generator in long-term castrates around the summer solstice. These results demonstrate that the very high LHRH release reported around the summer solstice in intact male rabbits (Lin \& Ramirez, 1991) are testes dependent. One explanation for this observation is that testosterone may play an important role in regulating or stimulating the increase in $\mathrm{LHRH}$ release. Gonadal steroids may play an important role in regulating the mechanism by which animals retain seasonal cues when confined to standardized and constant laboratory conditions. The animals in this study were raised under natural lighting and temperature conditions and transferred to a constant $12 \mathrm{~h}$ light: $12 \mathrm{~h}$ dark cycle. Previous studies have observed seasonal changes in intact rabbits when measuring changes in testicular size (Carson \& Amann, 1972; Lin \& Ramirez, 1991) as well as in LHRH release under a constant photoperiod (Lin \& Ramirez, 1991). In seasonal breeders, including rabbits (Boyd, 1987), hamsters (Urbanski \& Simpson, 1982; Turek et al., 1975), ground squirrels (Zucker \& Licht, 1983) and sheep (Pelletier \& Ortavant, 1987), castration does not eliminate the photoperiodic influence on concentration of LH in serum. In the present study, castration eliminated the natural changes in the activity of the LHRH neural apparatus observed between spring and summer in intact rabbits under a constant $12 \mathrm{~h}$ light:12 h dark photoperiod (Lin \& Ramirez, 1991). Whether changes in the length of the photoperiod affect the activity of the LHRH neural apparatus in castrated rabbits remains unknown.

There was an increase in LHRH released within 14 days after testosterone implants. In contrast, there were no changes in the amplitude and frequency of LHRH. These results suggest that testosterone stimulates the LHRH pulse generator by activating silent neurons which discharge the neuropeptide asynchronously. Castrated rabbits with testosterone implants with fairly constant concentrations of hormone show a different LHRH release pattern compared with the seasonal changes in LHRH release observed in intact animals that showed clear seasonal changes in testosterone concentration (Lin \& Ramirez, 1991). First, the testosterone implants caused an increase in mean LHRH release, but not in amplitude, whereas the seasonal changes in intact animals showed increases in LHRH release and amplitude. Second, the effects of testosterone occurred earlier than the large seasonal increases in LHRH release observed previously in intact animals. These findings suggest either that testosterone has an effect on LHRH release which is independent of seasonal changes or that the effect of testosterone can interact with seasonal changes and thus cause the summer solstice rise in LHRH release to occur earlier. If testosterone causes a shift in seasonal changes, the differences in LHRH release profiles between the castrates bearing testosterone implants and the intact animals must still be explained. It is possible that the 
release of testosterone in intact rabbits is pulsatile (Moor \& YoungLai, 1975) and therefore, the continuous release of testosterone from the Silastic capsules is not comparable to physiological conditions. Another explanation is that a metabolite of testosterone or other factors from the testes are also necessary to produce such dramatic seasonal changes. Testosterone replacement prevented the increase in LH, FSH and pituitary LHRH receptors after castration (Limonta et al., 1986); but testosterone propionate injections $\left(100 \mu \mathrm{g} \mathrm{kg}^{-1}\right)$ showed variable effects on $\mathrm{LH}$ concentrations in castrated male rabbits (YoungLai, 1978). This study showed a potent, but transient, effect of testosterone on LHRH release in castrated male rabbits. There have been several experiments in rats which concur with these findings and contradict the hypothesized classical negative feedback effect of testosterone at the hypothalamus (for review, see Kalra \& Kalra, 1989).

Further studies are needed to examine the role of testosterone on the regulation of seasonal changes in the LHRH pulse generator in greater detail.

We thank B. Sylavong for assistance with animal care and E. Wilks for typing this manuscript. This work was supported by an NSF grant (to V. D. Ramirez) and an NIH training fellowship (to W. W. Lin).

\section{References}

Bahr, J.M., Wang, S-C., Huang, M.Y. \& Calvo, F.O. (1983) Steroid concentrations in isolated theca and granulosa layers of preovulatory follicles during the ovulatory cycle of the domestic hen. Biology of Reproduction 29, 326-334.

Boyd, I.L. (1987) Gonadotrophin secretion and pituitary responsiveness to LHRH in castrated and intact male rabbits exposed to different photoperiods. Journal of Reproduction and Fertility 79, 627-633.

Boyd, I.L. \& Myhill, D.G. (1987) Seasonal changes in condition, reproduction and fecundity in the wild European rabbit (Oryctolagus cuniculus). Journal of Zoology, London 212, 223-233.

Caillol, M., Mondain-Monval, M., Meunier, M. \& McNeilly, A.S. (1990) Effect of ovariectomy at two periods of the year on LH and FSH basal concentrations and pituitary response to LHRH in the brown hare (Lepus europaeus). Journal of Reproduction and Fertility 88, 533-542.

Carson, W.S. \& Amann, R.P. (1972) The male rabbit. VI. Effects of ejaculation and season on testicular size and function. Journal of Animal Science 34, 302-309.

Culler, M.D., Valenca, M.M., Merchenthaler, I., Flerko, B. \& Negro-Villar, A. (1988) Orchidectomy induces temporal and regional changes in the processing of the luteinizing hormone-releasing hormone prohormone in the rat brain. Endocrinology 122, $1968-1976$.

Davis, G.J. \& Meyer, R.K. (1973a) FSH and LH in the snowshoe hare during the increasing phase of the 10-year cycle. General and Comparative Endocrinology 20, 53-60.

Davis, G.J. \& Meyer, R.K. (1973b) Seasonal variation in LH and FSH of bilaterally castrated snowshoe hares. General and Comparative Endocrinology 20, 6l-68.

Dluzen, D.E. \& Ramirez, V.D. (1985) In-vivo activity of the LH-releasing hormone pulse generator in castrated and intact male rats. Journal of Endocrinology $107,331-340$.
Dluzen, D.E. \& Ramirez, V.D. (1986) A miniaturized push-pull cannula for use in conscious, unrestrained animals. Pharmacology Biochemistry and Behavior 24, 147-150.

Dluzen, D.E. \& Ramirez, V.D. (1987) In vivo activity of the LHRH pulse generator as determined with pushpull perfusion of the anterior pituitary gland of unrestrained intact and castrate male rats. Neuroendocrinology 45, 328-332.

Elder, W.H. \& Finerty, J.C. (1943) Gonadotrophic activity of the pituitary gland in relation to the seasonal sexual cycle of the cottontail rabbit (Sylvilagus floridanus mearnsi). Anatomical Record 85, $1-15$.

Gitzen, J.F, \& Ramirez, V.D. (1987) PC-Pulsar: Pulsar pulse analysis. Psychoneuroendocrinology 12, I-III.

Hartter, D.E. \& Ramirez, V.D. (1985) Responsiveness of immature versus adult male rat hypothalami to dibutyryl cyclic AMP- and forskolin-induced LHRH release in vitro. Neuroendocrinology 40, 476-482.

Kalra, P.S. (1988) Testosterone (T) stimulates LHRH release in vitro: effects of castration. Proceedings of the 70th Annual Meeting of the Society of Endocrinology Abstract 1197.

Kalra, S.P. \& Kalra P.S. (1989) Do testosterone and estradiol-17ß enforce inhibition or stimulation of luteinizing hormone-releasing hormone secretion? Biology of Reproduction 41, 559-570.

Larsen, J.L. \& Odell, W.D. (1987) Prolactin alters luteinizing hormone pulsation characteristics in the intact and castrate male rabbit. Neuroendocrinology 45, 446-450.

Levine, J.E. \& Duffy, M.T. (1988) Simultaneous measurement of luteinizing hormone ( $\mathrm{LH})$-releasing hormone, $\mathrm{LH}$, and follicle-stimulating hormone release in intact and short-term castrate rats. Endocrinology 122, 2211-2221.

Legan, S.J. \& Karsch, F.J. (1980) Photoperiodic control of seasonal breeding in ewes: modulation of the 
negative feedback action of estradiol. Biology of Reproduction 23, 1061-1068.

Limonta, P., Ladizhenskaya, A., Gunsalus, G.L., Bardin, C.W. \& Thau, R.B. (1986) Regulation of pituitary gonadotropin-releasing hormone receptors by androgens in the male rabbit. Endocrinology 118, $340-347$.

Lin, W.W. \& Ramirez, V.D. (1988) Effect of pulsatile infusion of progesterone in the in vivo activity of the luteinizing hormone-releasing hormone neural apparatus of awake unrestrained female and male rabbits. Endocrinology' 122, 868-876.

Lin, W.W. \& Ramirez, V.D. (1990) Infusion of progestins in to the hypothalamus of female New Zealand White rabbits: effect on in vivo luteinizing hormone-releasing hormone release as determined with push-pull perfusion. Endocrinology 126, 26I-272.

Lin, W.W. \& Ramirez, V.D. (1991) Seasonal changes in the in vivo activity of the luteinizing hormonereleasing hormone ( $\mathrm{LHRH}$ ) neural apparatus of male rabbits monitored with push-pull cannulae. Journal of Reproduction and Fertility 91, 531-542.

Lincoln, G.A. (1976) Seasonal changes in the pineal gland related to the reproductive cycle in the male hare, Lepus europaeus. Journal of Reproduction and Fertility 46, 489-491.

Merriam, G.R. \& Wachter, K.W. (1982) Algorithms for the study of episodic hormone secretion. American Journal of Physiology 243, E310-E318.

Moor, B.C. \& YoungLai, E.V. (1975) Effects of anesthesia, rapid blood sampling and castration on testosterone and luteinizing hormone levels in the adult male rabbit. Journal of Steroid Biochemistry 6, 1527-1530.

Park, Y., Park, S.D., Cho, W.K. \& Kim, K. (1988) Testosterone stimulates LH-RH-like mRNA level in the rat hypothalamus. Brain Research 451, 255-260.

Pau, K.-Y., Orstead, K.M., Hess, D.L. \& Spies, H.G. (1986) Feedback effects of ovarian steroids on the hypothalamic-hypophyseal axis in the rabbit. Biology. of Reproduction 35, 1009-1023.
Pelletier, J. \& Ortavant, R. (1975) Photoperiodic control of $\mathrm{LH}$ release in the ram. I. Influence of increasing and decreasing light photoperiods. Acta Endocrinologica 78, 435-441.

Pickle, R.L. \& Ramirez, V.D. (1989) The effect of sequential castration and testosterone replacement therapy on in vivo LHRH secretion in the male rat. Proceedings of Annual Meeting of Society for Neuroscience, Abstract 528.4.

Ramirez, V.D., Ramirez, A.D., Slamet, W. \& Nduka, E. (1986) Functiona! characteristics of the luteinizing hormone-releasing hormone pulse generator in conscious unrestrained female rabbits: activation by norepinephrine. Endocrinology 118, 2331-2339.

Reed, T.E. (1979) Function of the female reproductive tract. In Domestic Rabbits Vol March/April American Rabbit Breeders Association Official Publication, pp. 8-10. Bloomington, IL.

Sawyer, C.H., Everett, J.W. \& Green, J.D. (1954) The rabbit diencephalon in stereotaxic coordinates. Journal of Comparative Neurology 101, 801-824.

Turek, F.W., Elliott, J.A., Alvis, J.D. \& Menaker, M. (1975) The interaction of castration and photoperiod in the regulation of hypophyseal and serum gonadotrophin levels in male golden hamsters. Endocrinology 96, 854-860.

Urbanski, H.F. \& Simpson, S.M. (1982) Photoperiodic suppression of gonadotrophin secretion in castrated male hamsters. Journal of Reproduction and Fertility 66, 299-303.

YoungLai, E.V. (1978) Luteinizing hormone response of castrated rabbits to treatment with testosterone propionate and estradiol benzoate. Neuroendocrinology 25, 22-31.

Zucker, I. \& Licht, P. (1983) Circannual and seasonal variations in plasma luteinizing hormone levels of ovariectomized ground squirrels (Spermophilus lateralis). Biology of Reproduction 28, 178-185.

Received 4 April 1991 